\title{
REDUTOS RURAIS: ESTRATÉGIA DE RESILIÊNCIA E INFRAESTRUTURA VER- DE URBANA. ESTUDO DE CASO EM VALINHOS, SP - BRASIL
}

\author{
Léa Yamaguchi Dobbert \\ Larissa Leite Tosetti $^{2}$ \\ Sabrina Mieko Viana ${ }^{3}$
}

1Arquiteta, mestre em Recursos Florestais pela Escola Superior de Agricultura "Luiz de Queiroz" da

Universidade de São Paulo, Piracicaba - SP. E-mail: leadobbert@yahoo.com.br

2Engenheira Agrônoma, mestranda em Recursos Florestais pela Escola Superior de Agricultura "Luiz de Queiroz" da Universidade de São Paulo, Piracicaba - SP. E-mail: laletosetti@usp.br

${ }^{3}$ Bióloga, doutoranda em Recursos Florestais pela Escola Superior de Agricultura "Luiz de Queiroz" da Universidade de São Paulo, Piracicaba - SP. E-mail: smieko@usp.br

\section{Resumo}

O presente estudo ressalta a importância da preservação e/ou requalificação dos redutos rurais na cidade de Valinhos (SP), como referências culturais que devem ser mantidas no processo de urbanização do município. Da coleta de dados à apresentação das informações, um quadro da atual situação dos redutos rurais é traçado no mapa da cidade a fim de contribuir para a educação e a informação da população como também do poder público sobre os valores histórico, cultural e social de tais redutos rurais inseridos na malha urbana de Valinhos. Ao enfatizarem-se os valores culturais desses redutos rurais, visa-se integrar a arquitetura residencial e o desenvolvimento econômico à preservação do patrimônio cultural singular da região. Apresentam-se, como propostas, possíveis intervenções de infraestrutra verde, orientando a dinâmica de crescimento do local seguindo um desenho ambiental sustentável, com base numa análise dos redutos rurais, avaliados como ordenadores do espaço e do território local, encontrados na malha urbana da cidade de Valinhos no Estado de São Paulo.

Palavras-chaves: patrimônio cultural, redutos rurais, desenvolvimento urbano, desenho ambiental, resiliência, infraestrutura verde. 


\title{
RURAL REMAINS: STRATEGY OF RESILIENCE AND URBAN GREEN INFRAS- TRUCTURE. CASE STUDY IN VALINHOS, SP - BRAZIL
}

\begin{abstract}
The present study highlights the value of preserving and / or upgrading rural remains in Valinhos-SP-Brazil, cultural landmarks that should be preserved in the process of urbanization of the city. From the data collection to the presentation of information, a picture of the current situation of rural remains is designed on the city map to help to educate and inform the public about the historical values. Cultural and social effects of these remains inserted in the urban and rural areas of Valinhos emphasize the values of cultural and rural remains that aims at integrating the residential architecture and economic development to preserve the natural heritage of the region. Proposals are presented like possible interventions on the green infra structure, guiding the dynamic local growth. Following a sustainable environmental design, based on an analysis of rural remains and evaluated as space and the local area orientation, found in the urban landscape of Valinhos city of São Paulo State.
\end{abstract}

Key words: cultural heritage, rural remains, urban development, environmental design, resilience, green infrastructure.

\section{INTRODUÇÃO}

O processo da urbanização pode ser abordado sob vários ângulos: do urbanismo, no que diz respeito ao planejamento e paisagismo desse espaço; da percepção, no que concerne aos sentimentos, valores e atitudes dos habitantes em relação ao espaço vivenciado, ou, ainda, do estudo das conexões entre as formas espaciais e a estrutura social. No caso brasileiro, a urbanização aconteceu atrelada à herança rural, como esclarece Ribeiro (1995), processo que se manifesta nas simples habitações construídas em meados do século XX, que vão configurando a forma urbana.

A crença de que o espaço "mais urbanizado é melhor" é frequentemente utilizada como uma evocação ao nível de desenvolvimento econômico de uma região, entretanto, esse pensamento é quase sempre dissociado do nível cultural e social de seu povo e até mesmo em termos de sustentabilidade. Considerando que o desenvolvi- 
mento das cidades brasileiras adotou modelos orientados para maior produtividade econômica e lucratividade, constituídas sobre interesses privados em detrimento dos coletivos, o planejamento do meio físico foi praticamente inviabilizado acarretando em cidades, incapazes de oferecer uma boa qualidade de vida aos seus habitantes (LOMBARDO, 2003).

A preservação do espaço rural, tanto física como culturalmente, tem se mostrado salutar em razão dos inúmeros benefícios que tal preservação proporciona, como: presença de áreas verdes, áreas permeáveis que evitam fenômenos semelhantes às "ilhas de calor", manutenção da biodiversidade, melhora na qualidade do ar, conforto térmico, entre outros. Do mesmo modo, a implantação ou enriquecimento da infraestrutura verde, que deve estar associada a esses espaços existentes, podem aperfeiçoar o desenvolvimento da cidade, visando o crescimento dos espaços naturais em redes capazes de desempenhar serviços ambientais e maximizar a qualidade ambiental. A infraestutura verde é definida por Franco:

"Podemos considerar infraestrutura verde como sendo áreas urbanas permeáveis ou semi-permeáveis, plantadas ou não que "prestam serviços" à cidade e apresentam algum grau de manejo e gerenciamento púbico ou privado. Das áreas pertencentes à infraestrutura verde de uma cidade destacamos os seguintes serviços prestados: 1- Melhora da qualidade do ar promovendo a saúde humana; 2- Seqüestro de carbono da atmosfera; 3- Amortização do balanço climático entre temperaturas baixas e altas no microclima urbano entre dia-noite e as estações do ano; 4- Proteção, conservação e recuperação da biodiversidade da flora e fauna na área urbana; 5- Contenção da erosão; 6- Promoção de atividades contemplativas, esportivas e de lazer; 7- Promoção da importância da paisagem como fator determinante da estética urbana; 8- Incremento do fator permeabilidade do solo urbano permitindo a percolação da água e portanto a redução de enchentes; 9- Articulação e conectividade entre espaços verdes; 10- Promoção da seguridade urbana; 11- Proteção de áreas de fragilidade ecológica; 12- Promoção de áreas de alto valor imagético, icônico e de identidade de lugares e sítios urbanos."

(FRANCO, 2010, p. 143)

A cidade de Valinhos, assim como boa parte das cidades brasileiras, sofre pressões 
diversas do mercado imobiliário que vem se estendendo em direção às áreas rurais. A urbanização corporativa guiada pelo interesse de grandes empresas e pela especulação imobiliária deixa de lado, na maioria das vezes, os compromissos e gastos sociais, culturais, ambientais, voltando-se somente para o maior ganho possível de lucros. (SANTOS, 2008) Dentro desse contexto, Argollo (2004) alerta que a urbanização do campo não deveria significar transformá-lo em cidade, e sim resgatar e valorizar a memória e a cultura de um povo, baseado nas condições rurais, sem dar a esse processo de transformação uma conotação folclórica ou jocosa, reconhecendo o potencial dos novos empreendimentos que, segundo o estudioso, além de prover sustentabilidade sócio-econômica, contribuem não só para a preservação ambiental, mas também para os valores culturais de um país ou região.

Observa-se muitas vezes, porém, que esse objetivo ao se urbanizar o campo não é atingido, pois o que ocorre, na realidade, é o fato de empresários do ramo imobiliário apresentarem maiores vantagens aos proprietários para que estes se desfaçam de suas propriedades, onde serão construídos grandes edifícios, condomínios horizontais, dentre outros tipos de empreendimentos. A urbanização causa, então, fortes impactos, muitas vezes irreversíveis, à região além de impossibilitar a prática de atividades consideradas tipicamente rurais. Infelizmente, atraídos por tais propostas, o homem com raízes no campo acaba por ceder à pressão do mercado, perdendo a identidade, a liberdade e a referência de sua origem.

"Para Kayser (1990:13), o rural é um modo particular de utilização do espaço e de vida social. Seu estudo supõe, portanto, a compreensão dos contornos, das especificidades e das representações do espaço rural, entendido, ao mesmo tempo, como espaço físico (referência à ocupação do território e aos seus símbolos), lugar onde se vive (particularidades do modo de vida e referência de identidade) e lugar de onde se vê e se vive o mundo (a cidadania do homem rural e sua inserção nas esferas mais amplas da sociedade" (WANDERLEY, 2000, p.88)

Atividades consideradas tipicamente rurais, praticadas e desenvolvidas nas cidades, encontram-se, muitas vezes, encobertas por incrementos urbanos, sendo, ainda assim, consideradas redutos rurais. Os costumes das pessoas, geralmente de origem rural, manifestam-se na cidade em pequenos espaços por meio de diversas atividades exercidas, como pequenas criações, plantio de hortas, ou mesmo a prática de 
costumes tipicamente rurais, que integram o que se pode denominar de um modo de vida, expresso, portanto, em sua habitação como herança rural.

"O caipira foi vítima de um traumatismo cultural marginalizado pelo despojo de suas terras, resistente ao engajamento no "colonato" e ao abandono compulsório de seu modo tradicional de vida.". (RIBEIRO, 1995, p.387)

Manterem-se vivos os costumes e as crenças do homem do campo, o "caipira", é o mesmo que não se deixar apagar a memória de um povo, cuja identidade não pode ser desprezada, assumindo-se, pois, a importância de sua herança cultural, bem como de suas referências.

Nesse sentido, Argollo (2004) reconhece que o patrimônio arquitetônico, juntamente com o patrimônio industrial existente no meio rural, compõe um conjunto ainda mais rico: o patrimônio cultural rural. Patrimônio que, inserido na malha urbana, vem definir a cultura e a paisagem da cidade:

"O papel da arquitetura rural no processo de resgate e valorização da memória e cultura local é fundamental para o desenvolvimento rural sustentável, uma vez que eles (memória e cultura locais) são a base para o reconhecimento e análise das paisagens culturais de uma determinada região" (ARGOLLO, 2004, p.8).

A palavra reduto, segundo Houaiss (2004), são espaços fechados ou recintos demarcados; sendo assim, redutos rurais urbanos podem ser definidos como espaços rurais fechados remanescentes inseridos na malha urbana.

Trabalhos de pesquisa que reconheçam a relevância de tais redutos são decisivos para propor a devida valoração e estímulo de preservação do rural. Por meio de incentivos fiscais, resgate da cultura local e apoio cultural, o Estado pode viabilizar o convívio harmônico entre urbanização e espaço rural. Muitas vezes a contenção do crescimento de uma cidade pode trazer vários benefícios à população que habita a região. 
Numa outra perspectiva, Herzog e Rosa (2010), retomando outros autores, defendem o desenvolvimento da ecologia da paisagem na ecologia urbana, como decisiva para a compreensão da interação homem-natureza, ao proporcionar uma mudança positiva no planejamento e adaptação das cidades. O mapeamento dos redutos rurais, ou remanescentes naturais, na área urbana podem ser de grande valia como auxiliares no diagnóstico e no planejamento urbano, visando a um desenho ambiental, definido por Franco (2008 p.212), "como a arte e a ciência dedicada à valorização da qualidade de vida das cidades....".

Esse mapeamento pode ser realizado com o uso de várias ferramentas, como os sistemas de informação geográfica (SIG), de imagens ou fotografias aéreas obtidas através de sensores remotos, dentre outros. Entretanto quando se trata de áreas ou municípios de pequeno porte (segundo IBGE, com 500 a 100.0000 habitantes), o levantamento dos dados pode ser feito em campo, com a vantagem de se possibilitarem levantamentos específicos quanto às estruturas arquitetônicas e às condições naturais (áreas verdes, parques, árvores, APPs urbanas).

Assim, conhecer os redutos rurais presentes em Valinhos (SP), estimular sua preservação e valorização, e utilizar esses espaços como resgate cultural e social, como oportunidade de presença do natural no urbano, como espaços educadores que aproximam os cidadãos de um conhecimento histórico e patrimonial, é uma alternativa de inclusão das pessoas em um pensamento holístico no desenvolvimento das cidades, visando sempre o crescimento que integra as diversas áreas do saber.

\section{OBJETIVO}

O presente estudo teve como objetivo apresentar um quadro dos redutos rurais, inseridos na malha urbana da cidade de Valinhos no Estado de São Paulo. O enfoque principal foi dado aos espaços públicos, às antigas sedes de fazendas e capelas, com o intuito de captar o modus vivendis rural, valorizando-se, assim, costumes e crenças a serem preservados, e realçando características da cultura rural local, sua história e seus valores. Compreende-se que a valorização desses redutos pode ser de grande valia no desenho ambiental urbano, auxiliando no desenvolvimento sustentável da cidade e, até mesmo, como forma de se levarem seus habitantes e gestores a refletirem sobre formas alternativas de crescimento do espaço rural no cotidiano das cidades. 


\section{MATERIAIS E MÉTODOS}

Valinhos localiza-se a $22^{\circ} 58^{\prime} 14^{\prime \prime}$ de latitude sul e $46^{\circ} 59^{\prime} 45^{\prime \prime}$ de longitude oeste, com altitude de 660 metros. Município criado em 1953, pertence à região Metropolitana de

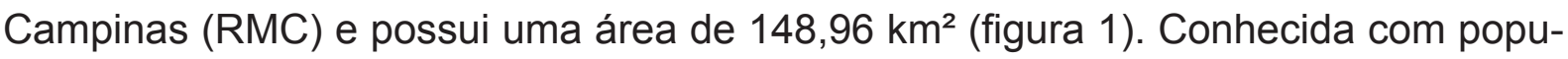
lação tipicamente de origem rural, hoje é ainda conhecida como capital do figo roxo.

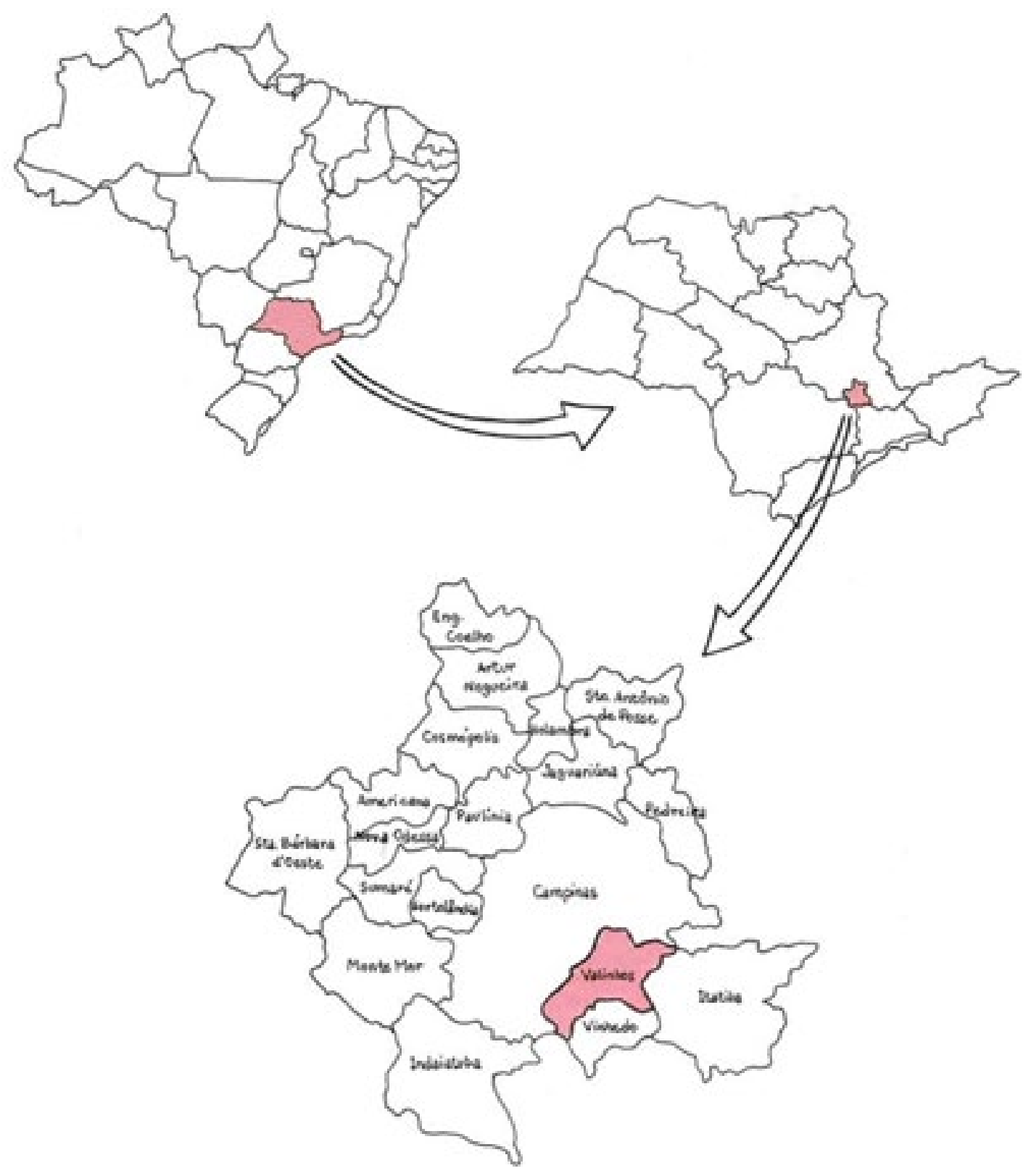

Figura 1. Localização de Valinhos a partir dos mapas do Brasil, do Estado de São Paulo e da região metropolitana de Campinas (ilustração: Sabrina Mieko Viana). 
Durante o mês de janeiro de 2007, realizou-se um mapeamento dos redutos rurais na malha urbana de Valinhos, por meio de levantamento de dados em campo, consulta a livros de registro, coleta (informal) de relatos de moradores locais, além de registro fotográfico.

Para se encontrarem as raízes de tal herança é importante que se conheça a história da cidade e de seus habitantes com o intuito de se compreender a origem desses costumes e da tradição rural. Para tanto, fez-se um levantamento bibliográfico referente à história da cidade de Valinhos, além da conversa informal com moradores locais.

Um estudo bibliográfico realizado anterior aos levantamentos de campo pôde auxiliar na compreensão do termo redutos rurais, definindo quais elementos da infraestrutura urbana entrariam nesse mapeamento.

\section{RESULTADOS E DISCUSSÃO}

A análise dos dados obtidos em pesquisa de campo indicia que os redutos encontrados dentro da malha urbana de Valinhos não estão adequados à cultura rural da região, levando-se em conta uma visão ecossistêmica, em que a diversidade tanto do ponto de vista biológico, ecológico, social e cultural é essencial na construção de cidades mais saudáveis e equilibradas (FRANCO, 2008).

Há necessidade, portanto, de se proporem novos modelos de gestão urbana, adequados à cultura local, que ressaltem a importância da preservação e ou requalificação dos redutos rurais arquitetônicos e culturais com a finalidade de que as referências culturais prevaleçam, inclusive com a inserção destas nos planos de gestão do município de Valinhos.

O levantamento dos redutos rurais pode ser observado na figura 2 . 


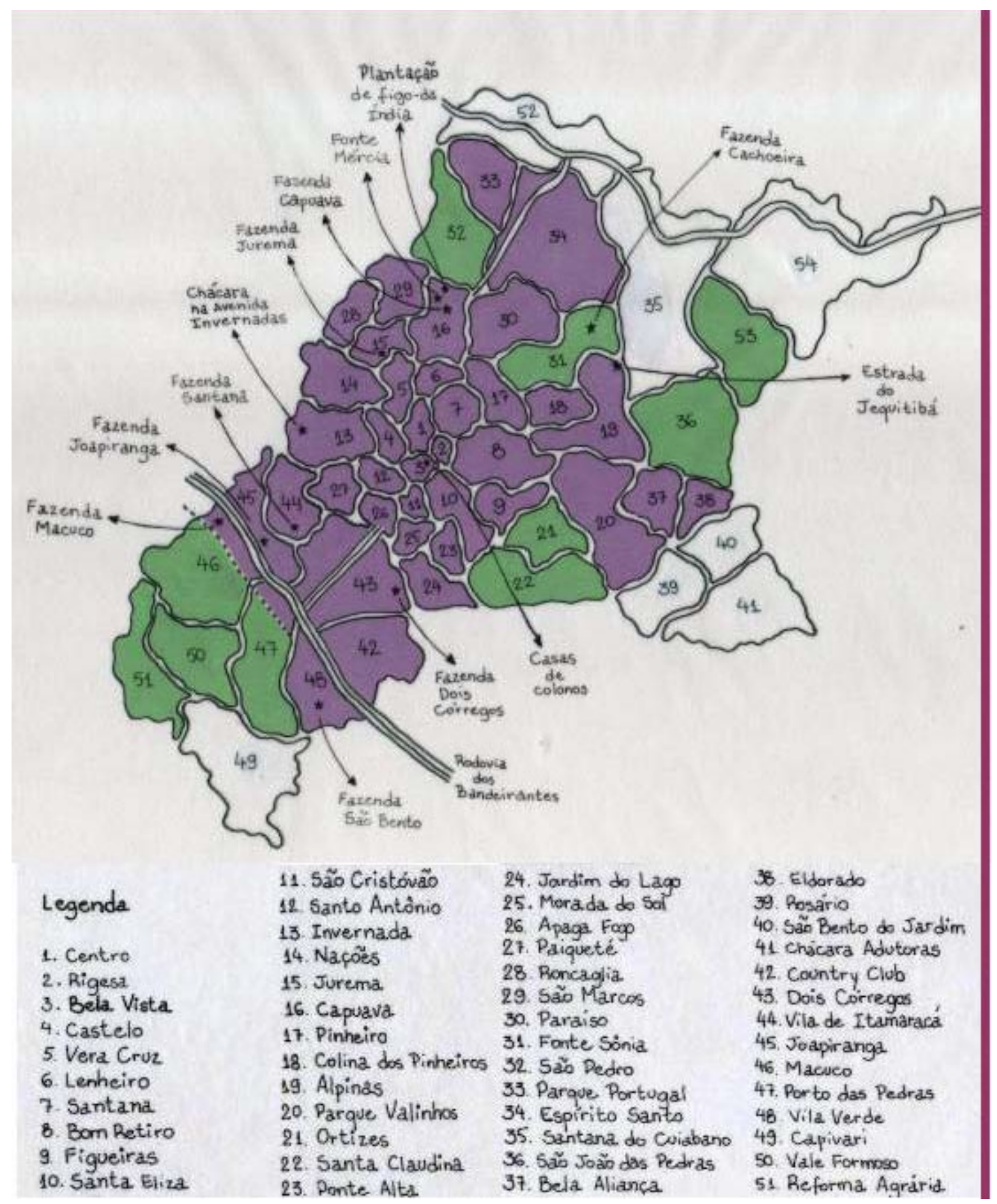

Figura 2: mapa de Valinhos e seus redutos rurais inseridos na malha urbana (ilustração: Sabrina Mieko Viana, baseado em mapeamento de Léa Y. Dobbert)

$\mathrm{Na}$ cidade de Valinhos, constatou-se que antigos espaços rurais foram transformados em escolas de equitação, pesqueiros, pousadas, clubes, residências de lazer e, especialmente, condomínios horizontais (figura 3 ). 

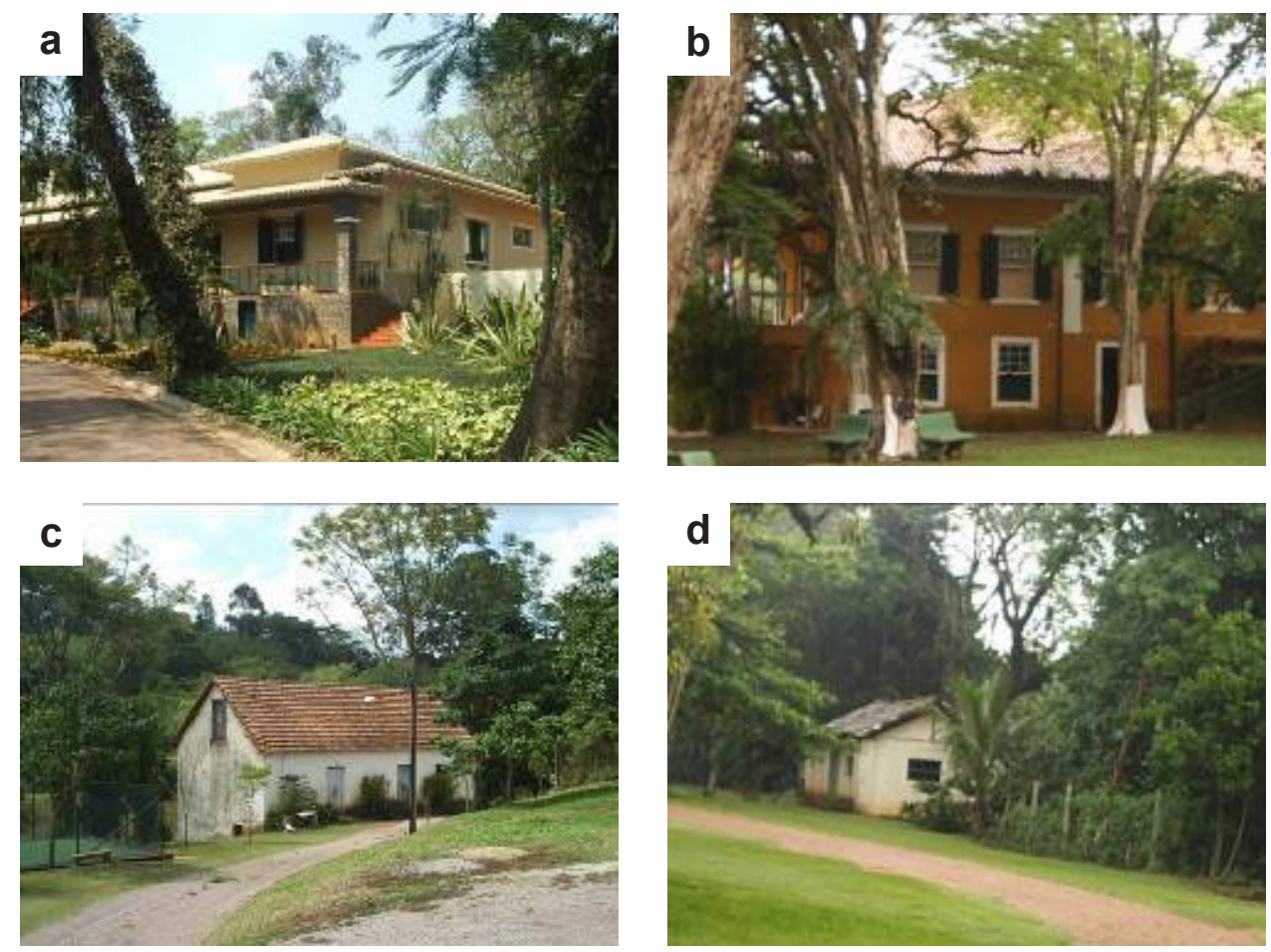

\section{Figura 3:}

a) Antiga fazenda Dois córregos, atual Condomínio residencial Reserva Colonial (Foto: Léa Yamaguchi Dobbert, 2007)

b) Antiga fazenda São Bento, atual clube de campo Vale Verde (Foto: Léa Yamaguchi Dobbert, 2007)

c) Antiga fazenda Santana, atual condomínio residencial Visconde Village do Itamaracá (Foto: Léa Yamaguchi Dobbert, 2007)

d) Antiga fazenda Macuco, atual Pousada Fazenda Joapiranga (Foto: Léa Yamaguchi Dobbert, 2007)

Há também antigas construções rurais como, por exemplo, algumas casas de colonos que se encontram atualmente sem utilização, expostas ao vandalismo devido ao descaso das autoridades locais (figura 4).
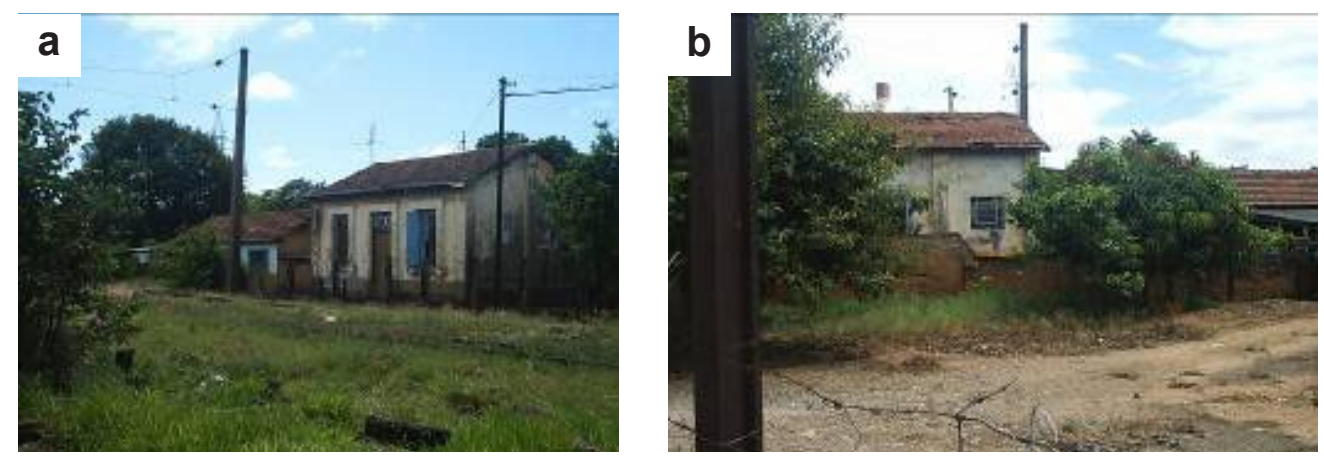

Figura 4: a) e b) Antigas casas existentes ao lado da Estação Ferroviária 
Outro aspecto importante a ser considerado ao se diagnosticarem e conhecerem os redutos rurais em Valinhos é o que se pode chamar de resiliência cultural e urbana, definida por Franco (2010) como "a capacidade que um determinado grupo social tem em resistir a mudanças provocadas pelo choque com culturas diferentes, preservando seu patrimônio cultural".

A pressão do mercado imobiliário, conforme relato de alguns moradores de pequenas casas de colonos de antigas fazendas, fez com que muitos destes moradores se redessem as propostas sedutoras de tais empreendedores, abrindo mão não apenas de seus imóveis, mas de sua tradição, memória e história.

Neste sentido, Menezes e Tavares (2003), destacam a importância de se respeitar a história urbana e social com seus significados, sentidos e valores simbólicos, por meio da conservação da imagem urbana. Ao preservar os redutos rurais de Valinhos, não se impede o desenvolvimento da cidade com as mudanças esperadas, mas, antes, garante-se que certos códigos simbólicos sejam mantidos naquela comunidade, valorizando-se, assim, a cultura local em meio às influências culturais exóticas e às pressões imobiliárias.

A capacidade de resiliência em um município é bem empregada quando utilizada para amenizar impactos antropogênicos, como esclarece Franco (2010). Assim, a proposta de parques lineares com funções de corredores verdes, que conectam os redutos rurais ao espaço urbano, permite um desenvolvimento mais harmônico do município ao assegurar a seus moradores e visitantes possibilidades variadas de lazer, locomoção e contato com a história e a cultura da cidade. Respeita-se, assim, a sobrevivência da cultura rural de Valinhos.

Em conjunto com esta proposta, sugere-se também que a população seja educada para reconhecer o valor histórico, cultural, social e ecológico, de tais redutos rurais inseridos na malha urbana de Valinhos. Neste contexto pode-se pensar nestes lugares também sob o conceito dos "espaços e estruturas educadoras", ou seja, como locais onde se possa trabalhar e discutir, com a população, alternativas para a sustentabilidade, por meio do estímulo à realização de atividades conjuntas, além do reconhecimento da necessidade de se educar (BRANDÃO, 2005).

Qualquer espaço no cotidiano das cidades pode ter características educadoras, entretanto para que isso se concretize, de fato, é necessário que haja uma intencionalidade 
educativa, levando as pessoas à reflexões sobre as causas e efeitos dos problemas urbanos, além de redescobrirem e resgatarem os simbolismos, a cultura, a história e as identidades associados à sua cidade (MATAREZI, 2005). Um espaço educador quando bem estruturado e pensado em suas intenções educadoras pode ter um potencial tão provocador e transformador quanto o de, por exemplo, uma obra de arte (MATAREZI, 2005). Considera-se também que a partir do momento que as pessoas reconhecem este patrimônio, o descobrem e se apropriam destes espaços, aumenta seu sentimento de pertencimento ao local, potencializando os esforços de conservação e preservação destes espaços, estabelecendo assim um elo afetivo com o lugar (TUAN 1980).

Incluídas nas possibilidades que o espaço educador oferece, podemos vislumbrar a viabilidade de implementar estruturas que auxiliem no resgate do pertencimento dos moradores urbanos aos equipamentos públicos, como as propostas de ciclovias, parques lineares, espaços arborizados para esporte e lazer e outras diversas formas de aproveitamento, formalizando infra-estruturas verdes que também atuam na melhoria ambiental do município.

Fundindo as oportunidades de aproveitamento dos espaços urbanos e fundamentando otimização dos investimentos no orçamento público, pretende-se realizar uma proposta de catalogação e documentação dos redutos rurais em Valinhos, que servirá de instrumento de consulta para se criar um organismo em defesa do patrimônio histórico e cultural do município, que auxilie no planejamento e investimento dessa infraestrutura verde necessária ao desenvolvimento da urbe.

\section{CONSIDERAÇÕES FINAIS}

Para que o planejamento e o projeto da infraestrutura verde em Valinhos sejam de fato eficientes e eficazes, é preciso ter uma abordagem sistêmica, abrangente e transdisciplinar. Sua eficácia depende de um levantamento detalhado dos aspectos abióticos, bióticos e culturais. Um mapeamento dos condicionantes geológicos, geomorfológicos, hídricos - de preferência com o uso da bacia hidrográfica como unidade de macroplanejamento -, climáticos, da cobertura vegetal, dos sistemas de drenagem e esgotamento sanitário e uso e ocupação do solo nessa região seria o passo inicial a fim de que se conheça a biodiversidade local. Levantar dados e mapas históricos sobre o uso e a ocupação do solo, hábitos da cultura local, é um segundo passo a ser dado. 
Conhecer, enfim, em profundidade o município. O processo do planejamento deve ser dinâmico e flexível, além de efetivamente participativo contando com representantes de todos os segmentos da sociedade que serão afetados pelo projeto. É necessário identificar os anseios e os problemas trazidos pela comunidade quando se buscam novas idéias que devem nascer como fruto da vivência e da experiência no lugar pesquisado. $\mathrm{O}$ engajamento dos usuários nas fases do planejamento e do desenvolvimento do projeto é essencial para que a infraestrutura verde seja sustentável em longo prazo (RIBEIRO, 2001; BOUCINHAS, 2007; COSTA et al., 2007). O diagnóstico inicial irá indicar quais as oportunidades e as limitações da área.

Urge, portanto, a necessidade de um estudo quali-quantitativo mais aprofundado e com maiores especificidades, que possibilite confeccionar um banco de dados contendo todos os redutos rurais e suas características para que se possa propor um método de catalogação e controle de preservação do patrimônio cultural rural da cidade de Valinhos (SP). Ao se propor também a conectividade entre esses redutos e a urbanização por meio de parques lineares ou corredores verdes, uma rota turística se fortalece com função ambiental, proporcionando um desenvolvimento urbano do município associado à implantação de infraestruturas verdes e a uma logística que facilite essas estruturas como espaços educadores.

\section{REFERÊNCIAS BIBLIOGRÁFICAS}

ARGOLLO FERRÃO, A. M. Arquitetura rural dentro do contexto dos estudos sobre patrimônio e paisagens culturais. Campinas: Barcelona [ESP]:ETSAB-UPC, 2004, p.p. 8-29.

BRANDÃO, C.R. Aqui é onde eu moro, aqui nós vivemos: escritos para conhecer, pensar e praticar o município educador sustentável. $2^{\mathrm{a}}$ ed. Brasília: MMA, Programa Nacional de Educação Ambiental 2005. 181p.

CARNEIRO, M.J. Ruralidade: novas identidades em construção. Rio de Janeiro: CPDA IUFRRJ, 1998, p. 4.

FRANCO, M.R.A. Desenho Ambiental: uma introdução à Arquitetura da Paisagem com o Paradigma Ecológico. $2^{\mathrm{a}}$ edição. São Paulo: Editora Annablume, 2008. 224p. 
FRANCO, M.R.A. 2010. Infraestrutura Verde em São Paulo: o caso do Corredor Verde Ibirapuera-Villa Lobos. Revista LABVERDE. n. 1, out. 2010, 134-154 p.

HERZOG, C.P., ROSA, L.Z. Infraestrutura verde: Sustentabilidade e resiliência para a paisagem urbana. Revista LABVERDE. n. 1, out. 2010, 91-115p.

HOUAISS, A.; VILLAR, M.S.; FRANCO, F.M.M., Minidicionário Houaiss da língua portuguesa, $2^{a}$ edição. Rio de Janeiro: Editora Moderna, 2004. 907p.

LOMBARDO, M.A. Qualidade ambiental e planejamento urbano In: RIBEIRO, W.C. (org.) Patrimônio ambiental brasileiro. São Paulo: EDUSP/Imprensa Oficial do Estado de São Paulo. 2003. 621p.

MATAREZI, J. Estruturas e espaços educadores: quando espaços e estruturas se tornam educadores In: FERRARO JÚNIOR, L.A. Encontros e Caminhos: formação de educadoras(es) ambientais e coletivos educadores. Brasília: MMA/Diretoria de Educação Ambiental. 2008. 358p.

MENEZES,M. e TAVARES, L.T., A imagem da cidade como patrimônio vivo, $3^{\circ}$ ENCORE, LNEC, Lisboa, 2003, 10p.

RIBEIRO, D. O povo brasileiro: A formação e o sentido do Brasil. Rio de Janeiro: Ed. Schwarcz, 1995, p.p. 198-397.

SANTOS, M. A Urbanização Brasileira. São Paulo: EDUSP. 2008. 174 p.

TUAN, Y. F. Topofilia, um estudo da percepção, atitudes e valores do meio ambiente. São Paulo: DIFEL, 1980. 288p.

WANDERLEY, Maria de Nazareth. A emergência de uma nova ruralidade nas sociedades modernas avançadas - o "rural" como espaço singular e ator coletivo. Estudos Sociedade e Agricultura. out. 2000. p.p.53-86. 